\title{
Growth of Hereford-Kedah Kelantan calves fed oil palm fronds and palm kernel cake based diet
}

\author{
I Sukri 1, MW Zahari 2, O Roslan 1 \\ 'MARDI, PO Box 525, 86009 Kluang, Johor ; 2MARDI, PO Box 12301, 50774 Kuala Lumpur, Malaysia
}

Being one of the world's leading producers of palm oil, Malaysia has a total of two million hectares of land under oil palm cultivation. The palm oil mills yield a number of by-products that are suitable for livestock feed such as palm kernel cake (PKC) and palm oil mill effluent (POME). In the farm, the important byproduct is the oil palm frond (OPF) which can be utilised fresh or ensiled. Hereford-Kedah Kelantan (HK) cows bred in a semi-intensive system were fed a palm kernel cake based diet supplemented with freshly chopped OPF at about $30 \%$ of dry matter (DM) intake. The diet was composed of PKC (55\%), POME (35\%), soya bean meal $(8 \%)$ and vitamin-mineral premix $(2 \%)$, all on a DM basis. All calves were weaned at the age of 3 months. Post-weaning calves were grouped by sex (eight animals per sex type) and offered a growing diet supplemented with about $15 \%$ of DM intake of freshly chopped OPF. The growing diet was composed of PKC (63\%), POME $(30 \%)$, soya bean meal $(5 \%)$ and vitamin-mineral premix ( $2 \%)$, on a DM basis.
The results showed that the male calves had higher birth weight, weaning weight and pre-weaning daily gain (ADG) than the female calves, however, the differences were non significant. Average birth weight of the calves was $20.2 \mathrm{~kg}$ for the males and $18.3 \mathrm{~kg}$ for the females. Pre-weaning ADG were $0.49 \mathrm{~kg}$ and $0.41 \mathrm{~kg}$ for males and females, respectively and they were better than that obtained in the open pasture system as reported by Ariff et al (1986, Tek Ternakan 2, 2, 61-68). These authors reported an ADG of $0.37 \mathrm{~kg}$ (average of male and female). The average weaning weight was significantly heavier $(P<0.05)$ for male calves $(65.4 \mathrm{~kg}$ ) than for female calves $(55.8 \mathrm{~kg})$. Males had also higher post-weaning ADG, 1-year body weight and feed efficiency than females. The post-weaning ADG was $0.78 \mathrm{~kg}$ for male calves and $0.62 \mathrm{~kg}$ for female calves. This experiment has demonstrated that HK calves fed diet composed of oil palm fronds and palm oil mill by-products produced good growth rate comparable to or even better than that obtained under open pasture system.

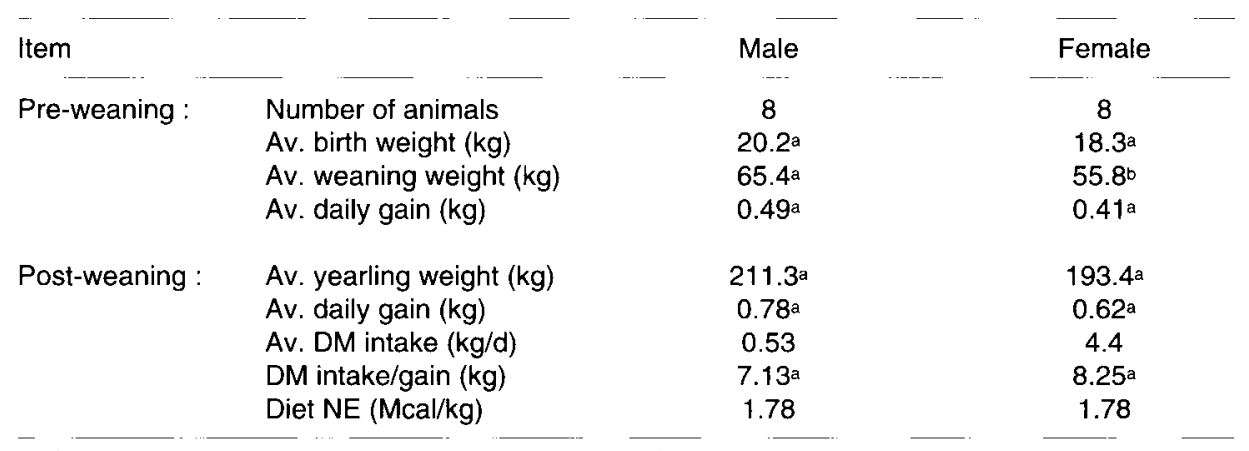

a, b Different letters within a row denote significance $(\mathrm{P}<0.05)$ 